\title{
Home is where the mouth is
}

\author{
Stephen Hancocks OBE \\ Editor-in-Chief
}

The BDJ Upfront section includes editorials, letters, news, book reviews and interviews. Please direct your correspondence to the News Editor,

Kate Quinlan at k.quinlan@nature.com. Press releases or articles may be edited, and should include a colour photograph if possible.

$\mathrm{H}$ ighly focussed as we are on our often intense and frequently hectic daily routines, activities and schedules we can be forgiven for overlooking the fact that our patients spend only a tiny sliver of their time with us in any given year compared to the oceans of their lives lived elsewhere. By the same token there is a similar dissociation for patients in that the special trip to see us is not necessarily connected with the rest of their waking concerns.

Reducing the risk of these disparate perceptions is firstly an important matter of awareness and secondly a key element to improving oral health; even when we are 'not there' and they are 'not here'. There is a gathering notion in the media at least, and arguably in society in general, that while ill health can be due to factors outside the individual's control, good health can be significantly affected by choices of lifestyle, especially diet and exercise. Taking this line of thought too far can tip into areas of victim blaming where issues of social disadvantage come into play but the broad sentiment holds true as a guiding principle.

However, reminding patients of the crucial part that they play in their own oral health and the value of this to their general health is something that it is all too easy to overlook when the focus is on detecting and dealing with disease. Yet missing this risks perpetuating the narrative that the patient is at the mercy of disease and is duty bound to passively revisit regularly to get it fixed.

Increasingly, with greater numbers of older people in the population, the further matter of dentistry at home also becomes a consideration and domiciliary care, once a fairly uncommon service, is now a much more regular occurrence. In the not too distant past this primarily consisted of the provision of dentures, mainly full-fulls with occasional partial dentures and extractions.
As more people keep more of their teeth for longer the balance of this treatment need has shifted too, meaning that restorative and to some extent periodontal care is also required. Consequently the sophistication of equipment needed has also been increased, although thanks to developments in materials, procedures such as the atraumatic restorative technique (ART) have introduced a greater range of options. For those clinicians who have experienced domiciliary care, few procedures in dentistry make one more aware of the intensity with which we usually practise compared to the time taken to travel, set up, examine, perhaps treat, take down and travel on again. A whole different mind set is required.

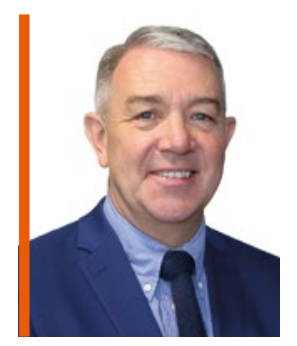

\section{'With greater numbers of older people in the population, the matter of dentistry at home also becomes a consideration'}

their teeth cleaned and also may not be able to communicate sufficiently accurately to describe pain or discomfort arising from their mouths.

Making the care home staff aware of the importance of good oral health is a further but equally important task that we need to consider as a profession. As above, there tends to be a disconnect between that which carers apply to themselves and their families in terms of oral care, and that which they perceive necessary for their charges at work. Yet, if anything, the need is far higher in the latter with much greater attention to detail. There are signs of improving awareness of oral health on the part of care homes, but pressure needs to be maintained before we can be sure that
For some, home is not necessarily the place where they live from choice but from necessity, by constraint or restraint. Such circumstances will include residential or care homes and long stay hospitals. Unless one is actively involved with these patient communities their needs probably do not consciously impinge on our day-today thought processes. These needs are nevertheless as crucial for their wellbeing as they are for those who are able to make it to the surgery. In the realm of care homes for older people though, we run into a slightly different set of circumstances since such care requires the close co-operation between a carer and a resident. Added to which, for reasons of dementia, for example, the resident may not be willing or able to have optimum conditions are in place universally.

The usual epithet is 'home is where the heart is' and it is tempting to stretch the analogy further to suggest that the heart and the mouth are more intimately connected now than ever thanks to the links being made between periodontal disease and cardiovascular health. What is certain is that imbuing in our patients the essential part that they can play in their own health is quite as important as the part we play a couple of times a year, or less. This does not lessen the value of our role but modifies it subtly to that of a partner in their wellbeing. As with so much in our profession the changing landscape of oral healthcare needs us to be more nimble than ever, at work and at home.

https://doi.org/ 10.1038/s41415-020-1320-5 